\section{IN brief}

\section{JOBS Act to jumpstart small business}

Early in April, President Barack Obama signed the Jumpstart Our Business Startups (JOBS) Act, a new law aimed at easing access to capital for young companies. The JOBS Act encourages small businesses and startups to raise funds through online 'crowdfunding', an approach to investment that captures some of the same networking techniques and energies that Twitter and Facebook bring to social communication. Companies are also given five-year exemptions from meeting stringent securities law requirements. "This legislation will make the pathway to capital formation more attainable for small biotechnology companies, encouraging American innovation by removing bureaucratic hurdles," says Jim Greenwood, president and CEO of the Biotechnology Industry Organization (BIO) in Washington, DC. It also will help them better "focus their limited funds on research rather than on compliance [and] will speed the development of new cures and treatments." The Washington, DC-based National Venture Capital Association (NVCA) also welcomes the JOBS legislation. It "will help revitalize an IPO [initial public offering] market that has suffered in recent years under the weight of market volatility and one-size-fits-all regulation," says NVCA chair Paul Maeder, a general partner at Highland Capital Partners, based in the Boston office of the international VC enterprise. "The passage of this legislation sends a strong and welcome signal to our most promising companies that the US capital markets system is open for business." Jeffrey $L$ Fox

\section{Wellcome partners to make drugs for India}

The Indian government and a UK charity are setting up an independent, not-for-profit company to fund the development of drugs and vaccines that specifically address diseases of major public health importance in India. On April 26 India's cabinet approved the joint venture formed by the Department of Biotechnology (DBT) and the London-based Wellcome Trust. The company, called 'R\&D for Affordable Healthcare in India, will be launched with a total investment of Rs 3.7 billion

(\$70.6 million), with each partner contributing equal amounts over the next five years. DBT secretary Maharaj Kishan Bhan says this new initiative is different from the two earlier DBTWellcome collaborations: an alliance launched in July 2010 (Nat. Biotechnol. 28, 996; 2010) was intended to support biomedical startups, and the fellowship program, which began in 2008 (Nat. Biotechnol. 26, 1202, 2008) was designed to attract Indian biomedical scientists working abroad back to their homeland. The latest venture will support research projects carried out at Indian public institutions and large biopharma companies. DBT expects to take products into early clinical trials through its newly-created Translational Health Science and Technology Institute in Gurgaon near New Delhi.

Killugudi Jayaraman

\title{
Shire drops 'emergency' Fabry's disease drug
}

In March, Shire withdrew its US marketing application for Replagal (agalsidase alfa) for treating the rare genetic disorder Fabry's disease. The move prompted surprise from industry observers and people affected by the life-threatening disorder, who might have benefitted from Shire's version of this enzyme-replacement therapy. "We are extremely disappointed that we feel compelled to make this decision," says Sylvie Grégoire, president of Shire Human Genetic Therapeutics, a business unit of the Dublin-based biotech. Shire submitted its Biologic License Application (BLA) to the US Food and Drug Administration (FDA) in November 2011 and was expecting a speedy review. But also in March, Genzyme of Cambridge, Massachusetts, now part of Paris-based Sanofi, resumed shipments of its own product, Fabrazyme (agalsidase $\beta$; recombinant human $\alpha$-galactosidase A), the only treatment for Fabry's disease approved in the US. Fabrazyme's reappearance, thus, is the practical impetus behind Replagal's removal from the US market but does not fully explain why Shire so quickly withdrew its BLA.

In 2009, Genzyme's product had been in short supply for several years following viral contamination problems at their Allston, Massachusetts plant (Nat. Biotechnol. 27, $681,2009)$. At the time, agency officials invited Shire to bring Replagal into the US market on an emergency basis and also to submit its BLA, says Jessica Mann of Shire. "We have no plans to reinstate the $B L A$, [which was] submitted at the special request of the FDA." After winning FDA licensure for Fabrazyme in the US in 2004, Genzyme became the sole supplier of treatment for US patients, and orphan drug status provided seven-year exclusivity (Nat. Biotechnol. 28, 1139-1140, 2010).

Shire withdrew its BLA "on examination of the briefing documents that the FDA circulated," Mann says. These documents were assembled for an anticipated advisory committee to review Replagal for safety and efficacy, despite the emergency use of Shire's treatment by Fabry patients during the supply shortages. Furthermore, FDA raised no safety concerns regarding Replagal.

Shire's drug has been approved in Europe, so in terms of market share elsewhere, it accounts for " $82 \%$ and over 2,800 patients worldwide," Mann says. After consulting with several "independent experts," Shire concluded that the FDA advisory committee "would have been given no choice but to recommend further trials. We had said from the outset that we would not be conducting clinical trials."

"For the majority of Fabry patients, both products work equally well as long as patients receive full doses," says Jack Johnson, executive director of th Concordia, Missouri. However, he adds, "A handful of US patients develop antibodies on Fabrazyme but tolerated Replagal. For them, the situation is more crucial and, so far, there is no means for them to continue getting this product. Our organization would like to see patients have a choice, the same as allowed in Europe. We hope Shire will change its decision and come back to the US."

"Our chief concern is for patients to get the treatment they need," says Mary Dunkle, vice president for communications at the National Organization for Rare Disorders in Danbury, Connecticut. "For that reason, we're disappointed that this treatment option will no longer be available to patients. Beyond that, we can't comment."

At least one other company, Amicus Therapeutics of Cranbury, New Jersey, is actively developing a therapeutic for patients with Fabry's disease - migalastat $\mathrm{HCl}$, an investigational oral pharmacological chaperone that is in phase 3 development. If approved, London-based GlaxoSmithKline holds an exclusive global license to make and market this product.

Jeffrey L Fox Washington, $D C$ 